\title{
THE HYDROGEN ION TITRATION OF TAIWAN COBRA NEUROTOXIN AND CARDIOTOXIN
}

\author{
YEE-HSIUNG CHEN *, BIN-TAO PAN and CHAN-PING LEE \\ Institute of Biochemical Sciences, College of Sciences, National Taiwan University, and Institute of Biological Chemistry, Academia \\ Sinica, Taipei, Taiwan 107 (China)
}

(Received August 27th, 1981)

(Revised manuscript received November 2nd, 1981)

Key words: Neurotoxin; Cardiotoxin; $\mathrm{H}^{+} ; \mathrm{pH}$ titration; (Taiwan cobra)

The $\mathrm{H}^{+}$titration curves for Taiwan cobra neurotoxin and cardiotoxin were performed over the interval $\mathrm{pH}$ 3.0-11.0. The isoelectric point was estimated to be 9.90 for neurotoxin and 10.60 for cardiotoxin. In the neurotoxin molecule, one of the seven carboxyl groups, one of the two imidazole groups and none of the four amino groups and six guanidino groups were found to be masked from the titration. In the case of cardiotoxin, all of the three carboxyl groups, ten amino groups and two guanidino groups were found to be titratable. Treatment of the titration data with the Linderstrom-Lang equation revealed further that: (1) the $p K_{\text {int }}$ of each titratable group in both toxins is virtually the same as for the corresponding small model compound; (2) both toxins expand when the $\mathrm{pH}$ of the protein solution is removed from their isoelectric points.

Two main kinds of toxin occur in the venom of Taiwan cobra [1]. One is the neurotoxin, which by inhibiting the binding of acetylcholine to its receptor causes blockade of the neuromuscular junction [1-3]. The other is cardiotoxin, cytolysin, cytotoxin or membrane-active-polypeptide, which exhibits versatile activities such as membrane depolarization, muscle contracture, cytolysis, etc. [4]. The primary structure of the neurotoxin has been determined and chemical modifications of its side chains have been described [2]. Recently, the tertiary structure of neurotoxins from the venom of the sea snake Laticauda semifasciata, a homolog of cobra neurotoxin, has been established by X-ray crystallography $[5,6]$. The primary structure of the cardiotoxin has been established $[7-11]$. The roles of the disulfide bonds [12], the tyrosine residues

\footnotetext{
* To whom correspondence should be addressed.
}

[13] and the methionine residues [14] in maintaining the active conformation of this protein have been reported also. Both neurotoxin and cardiotoxin are basic polypeptides and they are compatible with solvents less polar than water $[15,16]$. The statistical method of Chou and Fasman [17] predicts no helical structure in these two polypeptide toxins [18]. This paper presents the hydrogen ion titration for these two proteins. The status of the charged side groups in both toxins are elucidated and electrostatic interactions among the charged groups are described.

Cobra neurotoxin and cardiotoxin were isolated and purified according to the published procedure [19]. These two proteins in water were deionized by passing their solution through a mixed bed resin column $(0.7 \times 7.0 \mathrm{~cm})$. Each deionized sample in $0.1 \mathrm{M} \mathrm{KCl}$ was first titrated from the isoionic point up to $\mathrm{pH} 11.0$ with $0.1 \mathrm{M} \mathrm{NaOH}$, and then titrated back to $\mathrm{pH} 3.0$ with $0.1 \mathrm{M} \mathrm{HCl}$. The 
amount of acid or base used in the titration of proteins at a given $\mathrm{pH}$ was corrected for the unbound forms by blank titration in $0.1 \mathrm{M} \mathrm{KCl}$. At a given $\mathrm{pH}$, the average number of $\mathrm{H}^{+}$ions dissociated from each kind of charged group was estimated by the well known HendersonHasselbach equation using the appropriate values for $\mathrm{p} K_{\text {int }}$. Calculation was repeated by varying the titratable number until the sum of the estimated values due to each group agreed with the value read directly from the titration curve. To preserve electrical neutrality, the relation $C_{\mathrm{P}} Z+C_{\mathrm{H}^{+}}=$ $C_{\mathrm{OH}^{-}}$must obtain at the isoionic point. Here, $C_{\mathrm{P}}$, $C_{\mathrm{H}^{+}}$and $C_{\mathrm{OH}^{-}}$represent, respectively, protein, $\mathrm{H}^{+}$and $\mathrm{OH}^{-}$concentration, and $Z$ is the net charge of the protein molecule. From this equation the net charge of the protein at its isoionic point was calculated. The isoelectric point of the protein solution was found at the $\mathrm{pH}$ in the titration curve shifted by the amount of $Z$ from the isoionic point to zero charge point. The titration data were analyzed further by the classical Linderstrom-Lang expression [21]. From this, the $\mathrm{p} K_{\text {int }}$ and the electrostatic interaction factor $(\omega)$ of each charged group were obtained. Table I summarizes the information obtained from the titration curves. Fig. I shows the titration curves for the two toxic polypeptides.

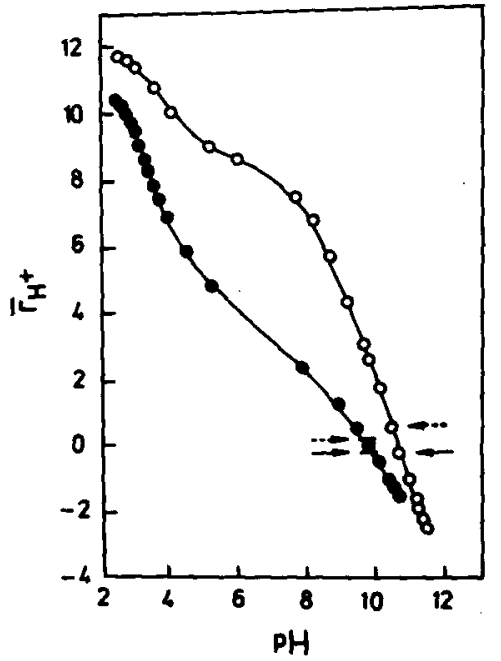

Fig. 1. The $\mathrm{H}^{+}$titration curves of the neurotoxin (- and the cardiotoxin $(\mathrm{O}-\mathrm{O})$. From the isoelectric point to a particular $\mathrm{pH}$, the positive and the negative $\bar{r}_{\mathrm{H}}+$ represent, respectively, the average number of $\mathrm{H}^{+}$associated with and dissociated from one protein molecule. The dashed arrow indicates the isoionic point and the solid arrow the isoelectric point.

The isoelectric point of the neurotoxin is at $\mathrm{pH}$ 9.90. The titratable sites read from the curve are 5.85 in the acidic region (pH 3.0-5.5), 2.40 in the neutral region $(\mathrm{pH} 5.5-8.5)$ and 3.95 in the al-

\section{TABLE I}

Titratable groups of neurotoxin (NTX) and cardiotoxin (CTX)

\begin{tabular}{|c|c|c|c|c|c|c|c|c|c|}
\hline & \multirow{3}{*}{$\begin{array}{l}\mathrm{p} K_{\text {int }} \text { expected } \\
\text { from data on } \\
\text { small molecules }\end{array}$} & \multirow{2}{*}{\multicolumn{2}{|c|}{$\begin{array}{l}\text { Number of } \\
\text { sites from } \\
\text { amino acid } \\
\text { sequence }\end{array}$}} & \multicolumn{6}{|c|}{ Data obtained from titration curve } \\
\hline & & & & \multicolumn{2}{|c|}{$\begin{array}{l}\text { Number } \\
\text { of sites }\end{array}$} & \multicolumn{2}{|l|}{$\mathrm{p} K_{\mathrm{int}}$} & \multicolumn{2}{|l|}{$\omega$} \\
\hline & & NTX & CTX & NTX & CTX & NTX & CTX & NTX & CTX \\
\hline$\alpha-\mathrm{COOH}$ & 3.8 & 1 & 1 & 1 & 1 & - & - & - & - \\
\hline Side-chain $\mathrm{COOH}$ & 4.5 & 6 & 2 & 5 & 2 & 4.6 & 4.6 & 0.08 & 0.06 \\
\hline Imidazole & 6.5 & 2 & - & 1 & - & 6.4 & - & 0.09 & - \\
\hline$\alpha-\mathrm{NH}_{2}$ & 7.5 & 1 & l & 1 & 1 & 7.5 & 7.5 & - & - \\
\hline Phenolic & 9.6 & 2 & 3 & $1^{b}$ & $2^{c}$ & $9.6^{\mathrm{b}}$ & $9.6^{c}$ & - & - \\
\hline Side-chain $\mathrm{NH}_{2}$ & 10.0 & 3 & 9 & 3 & 9 & 9.8 & 10.3 & 0.12 & 0.13 \\
\hline Guanidino & 12.5 & 6 & 2 & $6^{d}$ & $2^{d}$ & $>12$ & $>12$ & - & - \\
\hline
\end{tabular}

\footnotetext{
a From Tanford [20] and Nozaki and Tanford [26].

b By spectrophotometric titration and chemical modification [23].

c By spectrophotometric titration and chemical modification [13].

d From titration curve by procedure described in the text.
} 
kaline region $(8.5-11.0)$. Presuming all the ionic side chains of neurotoxin are exposed, calculation based on the Henderson-Hasselbach equation using the $\mathrm{p} K_{\text {int }}$ of small model molecules listed in Table I indicates that there should be $6.46,3.29$ and 4.70 titratable sites in the acidic, neutral and alkaline regions, respectively. The titratable sites read from the titration curve thus do not agree with expectations. Apparently, one ionic site in each of the three titration regions is masked from the titration. The inaccessible site in the alkaline region must be a phenolic group of one of the three tyrosine residues, in accord with the results of spectrophotometric titration and chemical modification [22]. Information collected from various sources (see, for example, Ref. 2) indicates that the $\mathrm{N}$ - and C-termini of cobra neurotoxin are exposed. Hence, the inaccessible site in the acidic region should be one of the six acidic residues and that in the neutral region should be one of the two histidine residues. By subtracting the forementioned three nontitratable sites from the total ionizable sites, one predicts $5.55,2.28$ and 3.85 titratable sites in the acidic, neutral and alkaline regions, respectively. These values are in good agreement with those read directly from the titration curve.

Cardiotoxin is devoid of histidine, so only the $\alpha-\mathrm{NH}_{2}$ should be titrated in the neutral region if it is exposed. Hence, the titratable sites in the neutral and alkaline regions are taken together for discussion. The titratable sites read from the titration curve are 2.60 for $\mathrm{pH} 3.0-5.5$ and 10.9 for $\mathrm{pH}$ 5.5-11.0, and the isoelectric point is at $\mathrm{pH} 10.6$. If all of the ionic groups of cardiotoxin are exposed, the titratable sites will be 2.59 in the acidic region and 12.33 in the neutral and alkaline regions, according to calculations based on the HendersonHasselbach equation. It seems that all of the carboxyl groups of cardiotoxin can be titrated and some of groups having a $\mathrm{p} K_{\text {int }}$ higher than 5.5 are not titrated in the region $\mathrm{pH} 5.5-11.0$. It is noted that two of the three tyrosine residues in cardiotoxin are exposed [13]. Recalculation by subtracting one ionizable site gives 11.37 titratable sites in region $\mathrm{pH} 5.5-11.0$. This is close to the value read directly from the titration curve.

At pH 3.0, all of the exposed cationic sites of a protein are positively charged. Hence, the number of $\mathrm{H}^{+}$ions absorbed by a protein from its isoelec- tric point to $\mathrm{pH} 3.0$ represents its total exposed cationic sites. Estimation from the titration curve indicates that 10.5 and 11.5 of such sites exist in one molecule of the neurotoxin and the cardiotoxin, respectively. Substrating the titratable cationic sites in the region $\mathrm{pH} 3.0-11.0$ from the total exposed cationic sites gives the number of arginine residues on the protein surface. This kind of estimation indicates that all six arginine residues of the neurotoxin and both arginine residues of the cardiotoxin are exposed (Table I).

The $\mathrm{p} K_{\text {int }}$ values for $\alpha-\mathrm{COOH}$ and $\alpha-\mathrm{NH}_{2}$ groups of proteins are considered to be the same as for corresponding small model compounds, so they are assigned values of 4.5 and 7.5 , respectively, according to Table 1 . The $\mathrm{p} K_{\text {int }}$ for the titratable phenolic group is 9.65 on the basis of spectrophotometric titration [13,22]. A Linderstrom-Lang plot can then be performed to determine the $\mathrm{p} K_{\text {int }}$ and $\omega$ values for each kind of charged group. Their values are listed in Table $I$. The titratable side-chain- $\mathrm{COOH}$ groups of both the neurotoxin and the cardiotoxin have the same $\mathrm{p} K_{\text {int }}$ as the model compound. The titratable imidazole group of the neurotoxin is also very similar to the model compound. With regard to the titratable side-chain- $\mathrm{NH}_{2}$, those in the neurotoxin have a slightly lower $\mathrm{p} K_{\text {int }}$, whereas those in the cardiotoxin have a slightly higher $\mathrm{p} K_{\text {int }}$ as compared to the model compound. The $\omega$ of both toxins decreases from the alkaline to the acidic region. This indicates an increase in the molecular dimensions of both toxins. Since the backbone folding of both the neurotoxin and the cardiotoxin shows no change in the region $\mathrm{pH} 3.0-11.0$ according to spectropolarimetric investigations $[15,16]$, the expansion of both toxins does not disrupt their active conformations.

Comparison of the results of this work with those obtained by other methods provides a better basis to understand the activity of charged side chains in both neurotoxin and cardiotoxin.

In addition to the $\mathrm{N}$ - and $\mathrm{C}$-termini, there are six acidic residues, two tyrosine histidine residues, two residues, three lysine residues and six arginine residues in the neurotoxin molecule. The present work indicates that, except for one carboxyl, one imidazole and one phenol, all of the ionizable groups in the neurotoxin are titratable. Modifica- 
tion of the neurotoxin with glycine methyl ester discloses that only Glu-21 is inaccessible [23]. This agrees with the present result. Since His- 32 can be photooxidized more easily than His-4 [24], the nontitratable imidazole group must be at His-4. The three lysine residues, namely Lys-26, Lys-27 and Lys-53, are titratable, and it has been shown that all of them can be guanidated [25]. However, trinitrobenzene sulfonate modifies Lys-27 and Lys-53 but not Lys-26 [25]. Perhaps the environment around Lys-26 hinders the access of trinitrobenzene sulfonate to the reaction site.

Besides the $\mathrm{N}$ - and $\mathrm{C}$-termini there are three acidic residues, three tyrosine residues, nine lysine residues and two arginine residues in the cardiotoxin molecule. As yet, no study of the status of the ionizable groups by chemical modification has appeared in the literature, except that two of the three tyrosine residues have been shown to be exposed [13]. As is evident from the fact that all the acidic and basic residues are titratable, these charged groups must be located on the surface of this toxic polypeptide.

\section{References}

1 Lee, C.Y. (1972) Annu. Rev. Pharmacol. 12, 265-286

2 Yang, C.C. (1974) Toxicon 12, 1-43

3 Tu, A.T. (1977) Venom: Chemistry and Molecular Biology, pp. 178-200, John Wiley and Sons, New York

4 Condrea, E. (1974) Experientia 30, 121-129

5 Tsernoglou, D. and Petsko, G.A. (1976) FEBS Lett. 68, 1-4

6 Low, B.W., Preston, H.S., Sato, A., Rosen, L.S., Searl, J.E., Rudko, A.D. and Richardson, J.S. (1976) Proc. Natl. Acad. Sci. USA 73, 2991-2994

7 Narita, K. and Lee, C.Y. (1970) Biochem. Biophys. Res. Commun. 41, 339-344
8 Hayashi, K., Takechi, M., Sasaki, T. and Lee, C.Y. (1975) Biochem. Biophys. Res. Commun. 64, 360-377

9 Takechi, M., Sasaki, T., Kenedá, N. and Hayashi, K. (1976) FEBS Lett. 66, 210-214

10 Kaneda, N., Sasaki, T. and Hayashi, K. (1976) Biochem. Biophys. Res. Commun. 72, 1450-1455

11 Kaneda, N., Sasaki, T. and Hayshi, K. (1976) FEBS Lett. 70, 217-222

12 Narita, K., Cheng, K.L., Chang, W.C. and Lo, T.B. (1978) Int. J. Peptide Protein Res. 11, 229-237

13 Hung, M.C., Pan, Y.H., Cheng, K.L. and Chen, Y.H. (1978) Biochim. Biophys. Acta 535, 178-187

14 Hung, M.C., Cheng, K.L., Lai, M.Z. and Chen, Y.H. (1977) J. Chin. Biochem. Soc. 6, 27-36

15 Chen, Y.H., Lo, T.B. and Yang, J.T. (1977) Biochemistry $16,1826-1830$

16 Hung, M.C. and Chen, Y.H. (1977) Int. J. Peptide Protein Res. 10, 277-285

17 Chou, P.Y. and Fasman, G.D. (1974) Biochemistry 13. 222-245

18 Chen, Y.H., Lu, H.S. and Lo, T.B. (1975) J. Chin. Biochem. Soc. 4, 69-82

19 Lo, T.B., Chen, Y.H. and Lee, C.Y. (1966) J. Chin. Chem. Soc. 13, 25-37

20 Tanford, C. (1962) in Advances in Protein Chemistry (Anfinsen, C.B., Anson, M.L., Bailey, K. and Edsall, J.T., eds.), Vol. 17, pp. 69-160, Academic Press, New York

21 Tanford, C. (1961) in Physical Chemistry of Macromolecules (Tanford, C., ed.) pp. 550, John Wiley \& Sons, Inc., New York

22 Chang, C.C., Yang, C.C., Hamaguchi, K., Nakai, K. and Hayashi, K. (1971) Biochim. Biophys. Acta 236, 164-173

23 Chang, C.C., Yang, C.C., Kurobe, M., Nakai, K. and Hayashi, K. (1971) Biochem. Biophys. Res. Commun. 43, 429-434

24 Huang, J.S., Lin, S.S., Ling, K.H., Chang, C.C. and Yang, C.C. (1972) J. Formosan Med. Assoc. 71, 383-388

25 Chang, C.C., Yang, C.C., Nakai, K. and Hayashi, K. (1971) Biochim. Biophys. Acta 251, 334-344

26 Nozaki, Y. and Tanford, C. (1967) Methods Enzymol. 11. 721 